\title{
WaterSocial.org as the social platform aimed to promote an efficient water use
}

\author{
Tomasz Jach \\ Institute of Computer Science, \\ University of Silesia, \\ 41-200 Sosnowiec, Bedzinska 39, Poland \\ Email: tomasz.jach@us.edu.pl \\ Ewa Magiera \\ Institute of Computer Science, \\ University of Silesia, \\ 41-200 Sosnowiec, Bedzinska 39, Poland \\ Email: ewa.magiera@us.edu.pl
}

\author{
Andrea Capiluppi \\ Department of Computer Science, \\ Brunel University London, UK \\ Email: Andrea.Capiluppi@brunel.ac.uk \\ Zhenchen Wang \\ Medicines \& Healthcare \\ products Regulatory Agency \\ London, UK \\ Email: zhenchen.wang@mhra.gov.uk
}

\begin{abstract}
ISS-EWATUS is a EU founded project which aims to increase the effectiveness of water saving awareness. One of its key components is the social media platform, along with connectors and information exchanging throughout whole system. In this paper, the brief description of this platform is stated, as well as the dissemination results of a whole ISS-EWATUS project.
\end{abstract}

\section{INTRODUCTION}

W ATERSOCIAL.ORG is an online social media platform (SMP) that was specially designed for promoting an efficient water use. This platform was designed and developed as a part of the project named Integrated Support System for Efficient Water Usage and Resources Management (ISSEWATUS) [1], [2]. By using this website, ISS-EWATUS has established a supportive community of users who are willing to take on the role of a "local leader" in changing the water behaviour of a local community[3]. This includes its impact on local, national and international levels across Europe and its target audiences of water stakeholders at different levels of individuals, households, green NPOs, water managers, researchers and policy makers. The SMP aims to ease the communication and creation of relationships between stakeholders and to produce a sustainable impact for the communities involved. Apart from supporting mainstream social networking activities such as sharing, communications, being friends, asking and answering, discussion, the SMP allows users to share water tips and photos under different environmental scenes, and the shared content can be pinned on a global map. Gamification enables the entire SMP to be used as a platform with gaming elements, which involve game tasks, competitions and rewards. The game tasks can be any user tasks on the social networks or any water use related offline activities such as recording water use activities. Each of these user tasks can be rewarded upon accomplishment. The rewards system has paid off in terms of acquiring users and convincing them to change their behaviour. Watersocial.org is unique in its vision to harness gamification and social media to reinforce water saving behaviours. It incorporates a set of gamification designs into the online social networking activities in which the users are able to get rewarded upon each accomplishment of a task or even are able to compete with each other through the WaterSocial.org leaderboards.

\section{GAMIFICATION IN WATERSOCIAL.ORG}

Gamification refers to the use of game design elements in non-game contexts such as gaining rewards from competition or participation. It can be used to engage communities of interest in changing behaviours. In the WaterSocial.org platform, the gamification mechanism is driven by three motivational affordances including Aqoins, Titles and Leaderboards. Aqoins and Titles can be won by participating to a variety of social networking activities; while the leaderboards allow users to compete with each other.

\section{A. Aqoins and titles}

Aqoins are points that used to reward user activities on the platform. In order to encourage more user activities, most of the activities can be used to earn Aqoins. Table 1 shows the tariffs of each activity: after completing any of the activities illustrated, users will be rewarded with the corresponding aqoins.

When a user earns certain amount of Aqoins, they can obtain titles (see Figure 1).

\section{B. Leaderboard}

The leaderboard aims to trigger more "social comparison" so that more user engagement can be achieved. There have been implemented three types of leaderboards, namely the weekly leaderboard within friend circle, monthly leaderboard within the whole community and the all-time leaderboard which includes all users throughout all time. 
TABLE I

USER ACTIVITIES THAT CAN EARN AQOINS

\begin{tabular}{|l|c|}
\hline User Activities & Aqoins \\
\hline submit data to water diary & 30 \\
\hline ask a new question & 30 \\
\hline answer a question & 10 \\
\hline reply an item from social stream & 10 \\
\hline like a topic & 10 \\
\hline vote a question/answer & 10 \\
\hline upload a photo from mobile app & 80 \\
\hline upload a photo on map & 60 \\
\hline post texts including tips on map & 30 \\
\hline reply a topic discussion & 20 \\
\hline
\end{tabular}

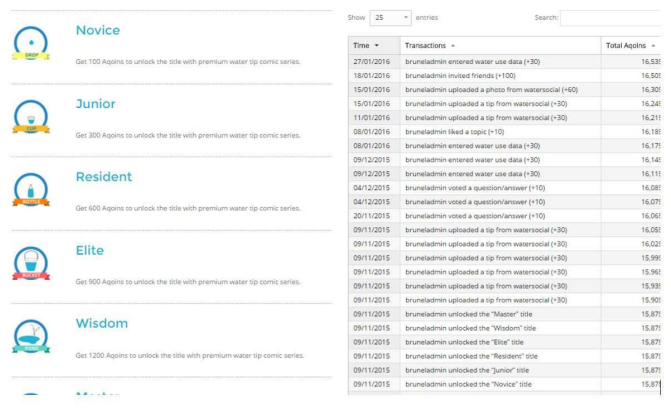

Fig. 1. My aqoins page

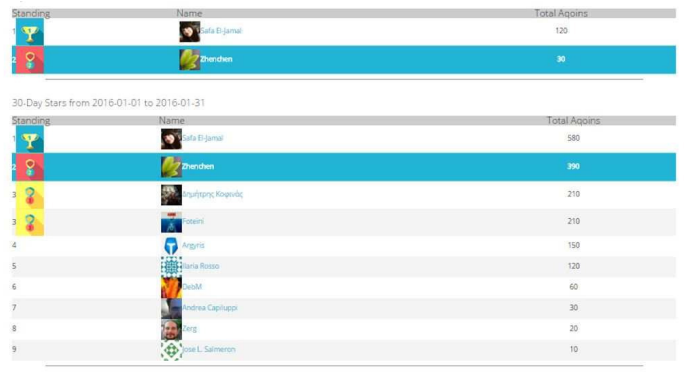

Fig. 2. Leader board page

\section{Social-MEdia PLATFORMS ENGENDERING SOCIAL ENGAGEMENT AND BEHAVIOUR CHANGE}

According to a report from Pew Internet Project3, as of early $201474 \%$ of the online adults use social networking sites. A qualitative study conducted in the UK by Binsted \& Hutchins [5] mapped individuals' usage patterns of social networks, namely: keeping in touch with contacts, sharing photos, playing games, following celebrities, organising social events, getting recommendations, as well as gaining and sharing information.

In addition to the general social network sites (e.g. Facebook, Twitter, and Google+), there are many other ones focused on specific topics. Some of them are linked to sports and life-style apps, such as Endomondo, RunKeeper, and WeightWatchers. These applications provide users with communities to exchange information about performances, to keep each other up-to-date, and to link their account with other networks. In the water conservation field the use of social networks are also emerging. For instance, Twitter has often been used as a media to share news and tips about water uses (Water-Use It Wisely).

Additionally, Facebook has been used to post water use related news to rise people's awareness of water conservation such as Water - Use It Wisely4. Since social networks are an emerging trend and their applications are growing very rapidly, it has a high potential to persuade people to practice water conservation.

\section{A. Social Engagement}

Self-gratification plays an important role in explaining why people tend to voluntarily take part in the social networks. It includes the gratification received from entertainment, information seeking, and social interaction [6], [7], [8]. Getting to know new people with common interest in order to share ideas seems to be one of the main reasons for people to use a social-media platform [9]. Furthermore according to the same research, people are interested in getting updates from their social network connections as this makes them better informed about other people's activities and opinions. In [10], self-gratification is further defined as one's attachment, sense of duty and good way to meet people, in the political context, which in turn are argued to play a major role towards influencing citizens to help curb social problems.

In addition to psychological factors, there are also other objective factors or incentives to cause people to join social networks. For example point systems (such as scores, stars, reputations and badges) are a common practice in many game applications. In some social forums, question and answer Websites, there is also an increasing number of computer and smartphone games that use point system to motivate players to keep playing the games. Reasons of why such a reward system is successful can perhaps be explained by using behavioural model of [11]. He argues that an activity that is easy to do (such as playing games) will require only low motivation for a person to finally do it. Thus, triggers, such as points, may be enough for making him/her play a game. However, when an activity is hard to do, it will require much higher motivation. Therefore, different kind of triggers may be needed to boost motivation.

\section{B. Social Behaviour Change}

Behaviour can be influenced through social norms. People are more likely to participate in an activity if those around are participating in the activity. Previous studies including [12] have also indicated that social media/networks can be used to motivate or to give certain pressure to people to behave in certain ways. One study performed in [13] showed that water conservation could be influenced by the presence of people modelling the promoted water saving action of turning off the shower while soaping. It was found that before the study $6 \%$ of shower users carried out the action while $93 \%$ were aware of the sign suggesting the action. Following the presence of 
one role model, $49 \%$ carried out the action. The presence of two role models resulted in $67 \%$ participation.

Behaviours can also be influenced via designed intervention. [14] defines a concept called CBSM (Community Based Social Marketing) referring to intervention programs that attempt to apply a structured approach and the insights of social psychology when influencing community behaviour. CBSM approach has been found to be effective in changing routine behaviour and the design of CBSM has been further developed in [15]. There four steps to design a CBSM, the first step involves recognising the behaviours relevant to a particular environmental goal, for example, installing a lowflow showerhead. CBSM starts with identifying the barriers which prevent the action from being taken, and then selecting a specific barrier to promote based on its potential impact on the behaviour campaign, the relevance to the behavioural change and the resources available to overcome the barrier. The chosen barrier varies depending on whether the desired behaviour change is a one off action, or involves changing a particular habit or routine. The study in [15] cognises that habitual or routine change is much more difficult to influence compared to changing a one-off behaviour. The second step is to design a programme to overcome the selected barrier to achieve the behavioural change. The important aspect of the design stage is to target interventions very specifically towards the identified barriers, drawing on social-psychological devices such as commitments, prompts, or signals, to promote the desired behaviours. The third and final steps in the CBSM approach are piloting and testing the programme and evaluating its effectiveness before it is applied on a wider scale.

\section{DESIGN AND IMPLEMENTATION OF WATERSOCIAL.ORG}

This chapter details the development aspects of WaterSocial.org. The system architecture, the components and their connectors are described, together with the process model and the data model of each component. The process model is needed to show the degree of interactions of the component with other components; the data model is needed to show the data structures and information flowing from one component to the other, as part of their interaction.

In the next few sections, each of the modules is presented in terms of process model, data model and their current deployment status in the system.

\section{A. Software components}

The software components are shown in Figure 3 (with the indication of which of the project tasks are implemented in). These components seek to fulfil the scenarios and the associated use cases defined in the gathered requirements via the following modules:

1) ISS-EWATUS Web Portal (ISNP): This is the landing Web page for the whole system.

2) ISNP Data Sensing (IDS): It detects social networking activities including sharing and inter-user communication and individual user water use input to the system.
IDS is cross-platform which means it also can receive data from multiple devices such as mobile phones and laptops. In addition, it also stores and dispenses the pre-processed data flows to other expected SMP components.

3) Water Use Visualizer (WUV): It performs the visualisation features which enable the system to present the water use patterns in different media forms such as charts, histograms from different dimensions such as temporal and activity.

4) Water Use Pattern Visualization (WUPV): This is the front end component that handles the user input from WUV.

\section{INTER-COMPONENT INTERACTIONS}

Interactions connect modules within components. Below we report, for each interaction, their process and data models, and the API specifications to implement these interactions. Also, the modules that are connected by each interaction are described. The modules are associated to three types of intercomponent interactions, as defined below:

1) Social Network Activity and Water Use Visualization

2) Gamification

3) Evaluation

Interactions connect modules within components. Below we report, for each interaction, their process and data models, and the API specifications to implement these interactions. Also, the modules that are connected by each interaction are described.

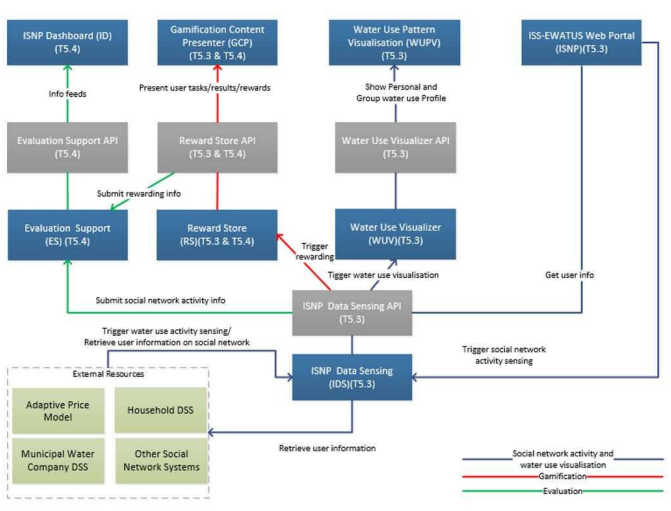

Fig. 3. ISS-EWATUS SMP Components

\section{A. Inter-component Interactions: Social Network Activity and Water Use Visualization}

This inter-component interaction has the purpose of handling, for each user account, the user account management; the social network activity management; and the water use visualization. The interactions that are allowed are two-fold:

1) internally to the SMP, its components interact through this layer at the user-level, 
2) externally, the interactions also extend to components outside the SMP, such as the household DSS (within the ISS-EWATUS scope) and the other social network systems (outside the ISS-EWATUS scope) to allow them to retrieve information provided by the platform.

1) Process model: Below we display the process model of the cluster of interactions named "Social Network Activity and Water Use Visualization". It is presented in a UML Sequence Diagram, where the main components are shown in their box, and the interactions are the arrows that travel between them.

At current implementation, we have enable the new user registration, post/reply and water use diagram request processes.

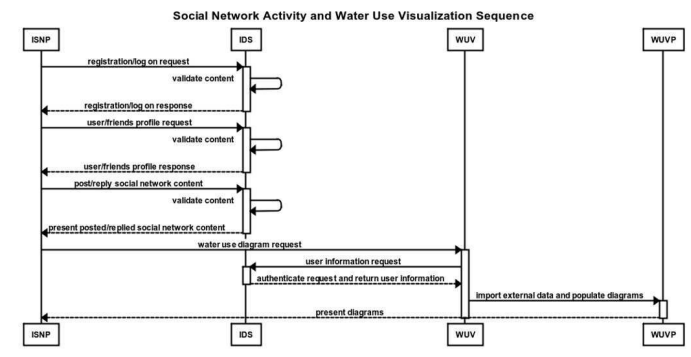

Fig. 4. Process model for social network activity and water use visualisation

2) Data Model: The data model used in the platform customises and extends the data structure supplied in the WordPress database framework. There are mainly three types of data types used in this module.

1) user: contains user information that comprises the use profile,

2) posts: defined as a base data structure used to be extended and implemented to define user input and other component data input to SMP,

3) postmeta: used to define the additional data fields in forms of key-value pairs of an extended posts type.

Figure 5 shows the user data structure, the full details of data field definition can be viewed on http://watersocial.org/ extensions-json/rest/api/users/schema.

Figures 6 and 7 show the base posts type and post meta data type data structures. In the platform we particularly extended the base posts type in terms of the post_type data field which allow the platform to handle different social networking activities input (see Table II). We also implemented three platform original data types used to handle user input of water use, water use tips and water use images, namely the tips object (see Figure 8), media object (see Figure 9). The descriptions of data fields of these two objects can also be found at http://watersocial.org/extensions-json/rest/api/tips/schema and http://watersocial.org/extensions-json/rest/api/media/schema.

As the platform is a Web-based application system, we developed a set of Web APIs (application programming interface) which allow the platform data can be accessed and managed within and outside the platform. The Web API here is defined as an API for either a Web server or a Web browser.

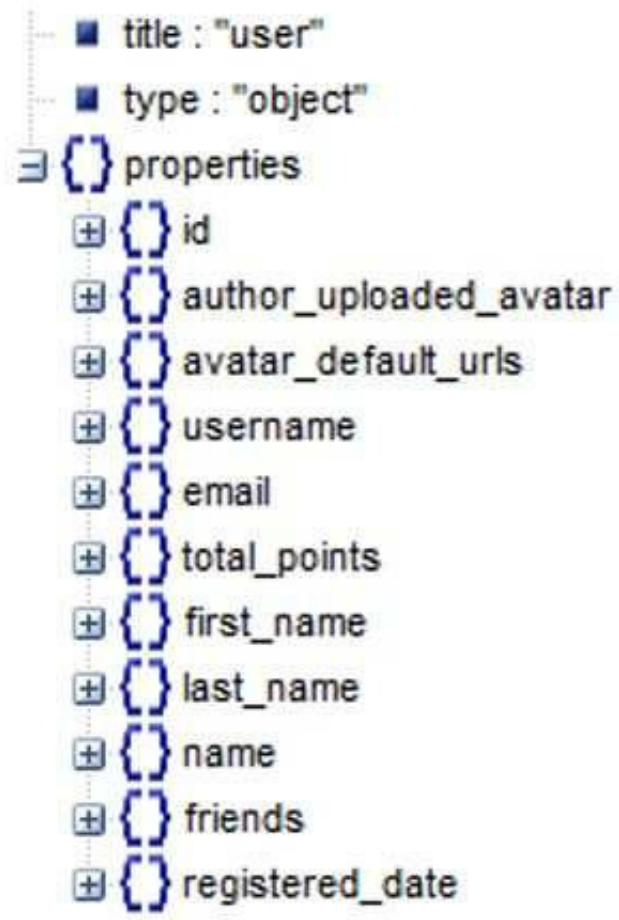

Fig. 5. User type data structure

TABLE II

CUSTOMIZED POST TYPE USED THE PLATFORM

\begin{tabular}{|l|l|}
\hline $\begin{array}{l}\text { Post Type Used in the } \\
\text { Platform }\end{array}$ & Use \\
\hline achievement-type & $\begin{array}{l}\text { To store different types of the gamification } \\
\text { tasks }\end{array}$ \\
\hline answer & $\begin{array}{l}\text { To store users answers in the Questions } \\
\text { and Answers activities }\end{array}$ \\
\hline attachment & $\begin{array}{l}\text { To store user uploaded content such as } \\
\text { images }\end{array}$ \\
\hline badge-log-entry & To log users'rewarding transactions \\
\hline bgmp & $\begin{array}{l}\text { To store geo-related content such as tips } \\
\text { and photos }\end{array}$ \\
\hline faq & To store FAQs of website \\
\hline forum & To store different types of forums \\
\hline mobilechallenge & $\begin{array}{l}\text { One of the achievement-type defined for } \\
\text { mobile users }\end{array}$ \\
\hline question & $\begin{array}{l}\text { To store users' questions in the Questions } \\
\text { and Answers activities }\end{array}$ \\
\hline reply & To store users' replies for a forum topic \\
\hline title & $\begin{array}{l}\text { One of the achievement-type defined for } \\
\text { all users }\end{array}$ \\
\hline topic & To store users' topics in a forum \\
\hline watersocial_survey & To store survey answers \\
\hline wateruse & $\begin{array}{l}\text { To store water use diary input from } \\
\text { individual users }\end{array}$ \\
\hline contact_form & $\begin{array}{l}\text { To log messages sent to users from } \\
\text { manager }\end{array}$ \\
\hline
\end{tabular}

The INSP and IDS components expose a set of Web APIs by using Restful Web services. This allows the SMP to be flexibly integrated with heterogeneous systems including Android and/or iOS apps. The APIs are well documented 


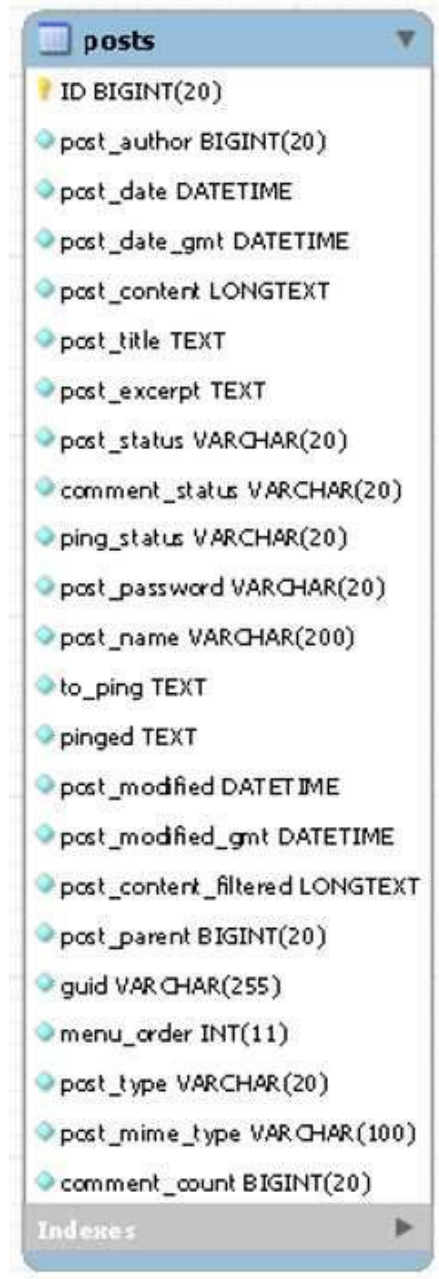

Fig. 6. Posts type data structure

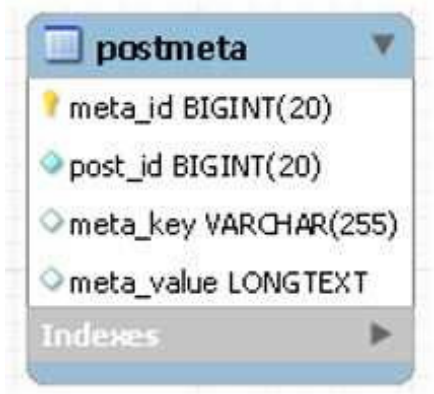

Fig. 7. Post meta data structure

in thehttp://watersocial.org/extensions-json/rest/api where IDS and WUV APIs are included and general descriptions of these APIs are given below (see Table III and Table IV).

\section{B. Inter-component Interactions: Gamification}

The gamification enables the whole SMP to be used as a platform with gaming elements, which involve game task,

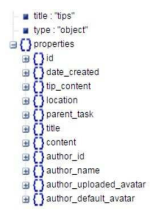

Fig. 8. Tips object, the full schema definition can be found at http: //watersocial.org/extensions-json/rest/api/tips/schema

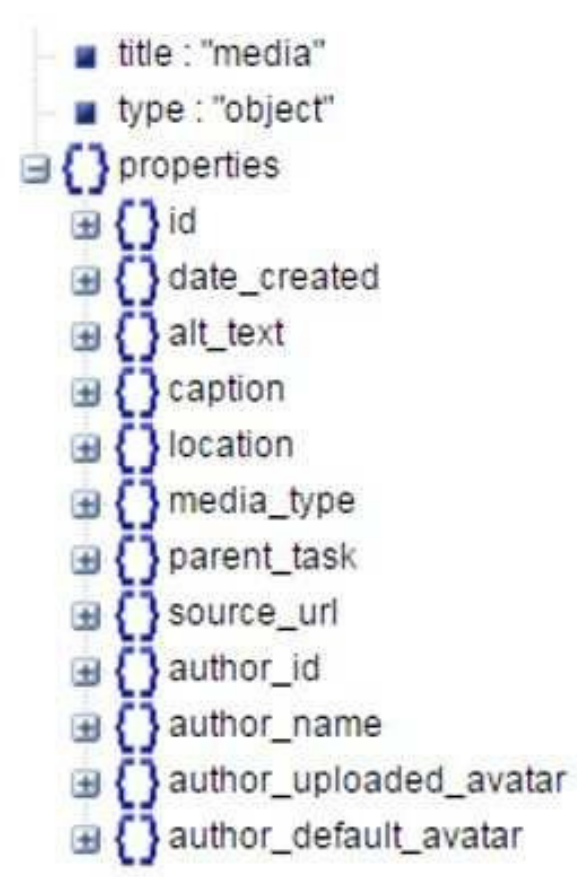

Fig. 9. Media object, the full schema definition can found at http://watersocial. org/extensions-json/rest/api/media/schema

competition and rewarding. The game tasks can be any user tasks on the social networks or any water use related offline activities such as recording down water use activities. Each of these user tasks can be rewarded upon its accomplishment. The gamification mechanism provided here allows managers to design user tasks and to reward points/badges as the user task progresses. The components involved include:

- Reward Store (RS) plays a pivotal role in incentivising users participating in the whole system. The features of RS include calculation of rewards such as points, experience level, ranking etc. for each gamified social network activity. RS outputs the rewarding results in the forms of leaderboard of users and notification of rewards on an individual basis.

- Gamification Content Presenter (GCP) is a front end component which handles information from RS.

1) Process Model: The gamification process involves user task design, task status check and rewarding procedures (see Figure 10). 
TABLE III

IDS APIS

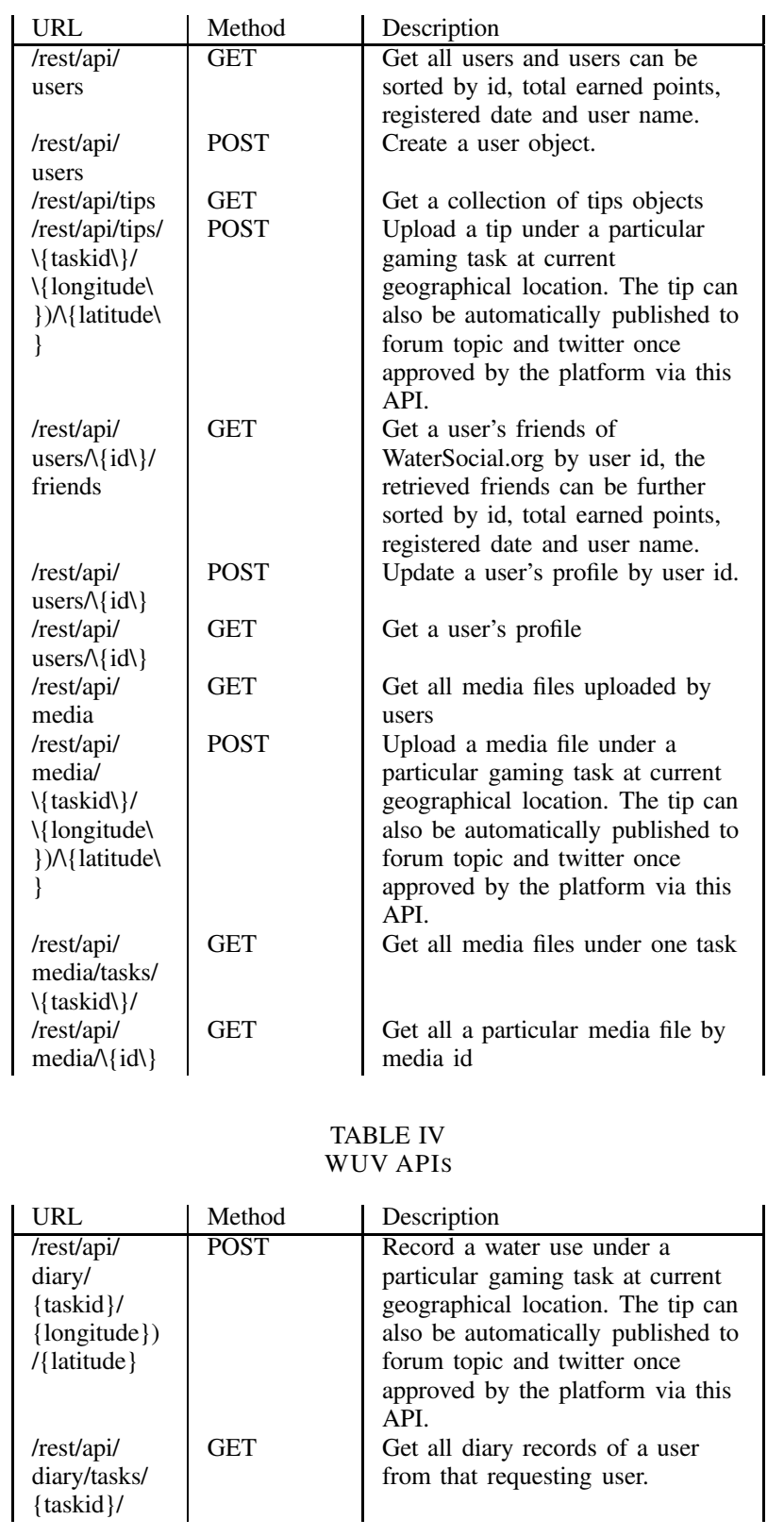

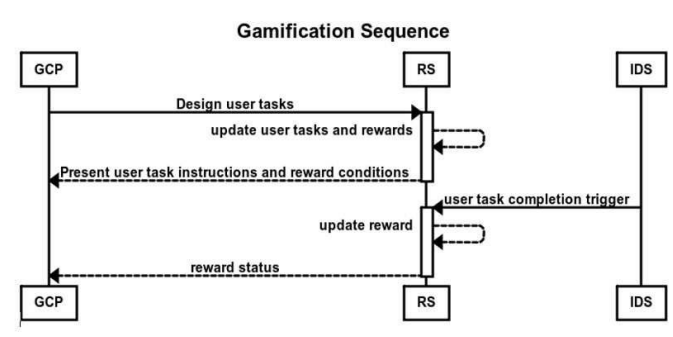

Fig. 10. Process model for gamification
2) Data Model: There are two data objects defined in this module namely the task object and reward object. The specifications of two objects are defined online. The tasks object is defined in http://watersocial.org/extensions-json/rest/api/tasks/ schema (see Figure 11) and the reward object is defined in http: //watersocial.org/extensions-json/rest/api/rewards/schema (see Figure 12).

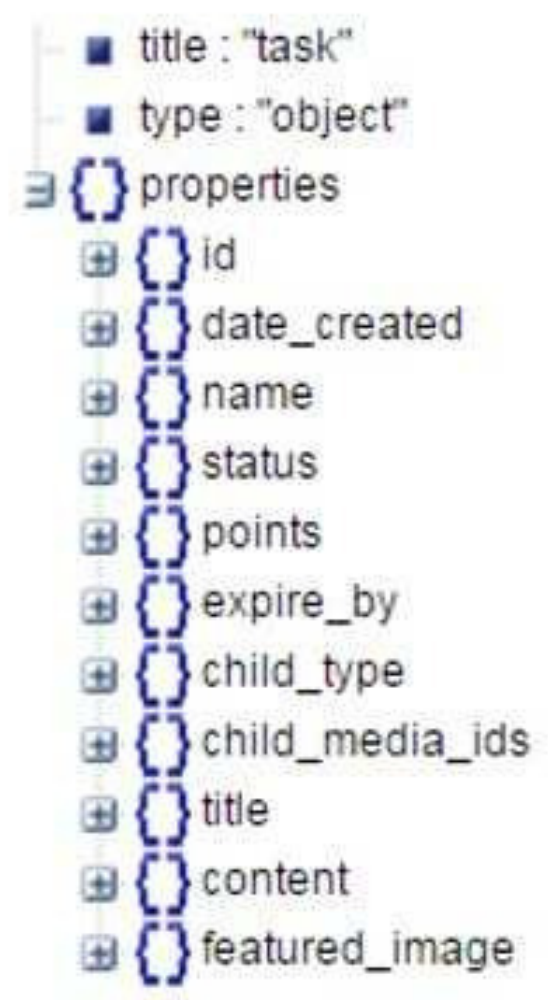

Fig. 11. Task object, the full schema definition can be found at http: //watersocial.org/extensions-json/rest/api/tasks/schema

The Web APIs for RS include those used to retrieve the points from the platform and those from the external game service providers (see Table V).

TABLE V
RS APIS

\begin{tabular}{|l|l|l|} 
URL & Method & Description \\
\hline $\begin{array}{l}\text { /rest/api/ } \\
\text { rewards/ } \\
\text { /userid }\} \\
\text { /rest/api/ } \\
\text { rewards/ } \\
\text { game }\end{array}$ & GET & Get a rewards of a user. \\
$\begin{array}{l}\text { /rest/api/ } \\
\text { rewards/ } \\
\text { game/ } \\
\text { decrypt/ } \\
\text { fcode }\end{array}$ & GET & $\begin{array}{l}\text { Get point redemption code from } \\
\text { watersocial, this API is used to } \\
\text { integrate the games from outside } \\
\text { the platform. } \\
\text { Get points value from a rewarding } \\
\text { code. This code is generated from } \\
\text { WaterSocial.org for external game } \\
\text { service provider. }\end{array}$ \\
\hline
\end{tabular}

In addition to the Web APIs, there are also APIs that used 


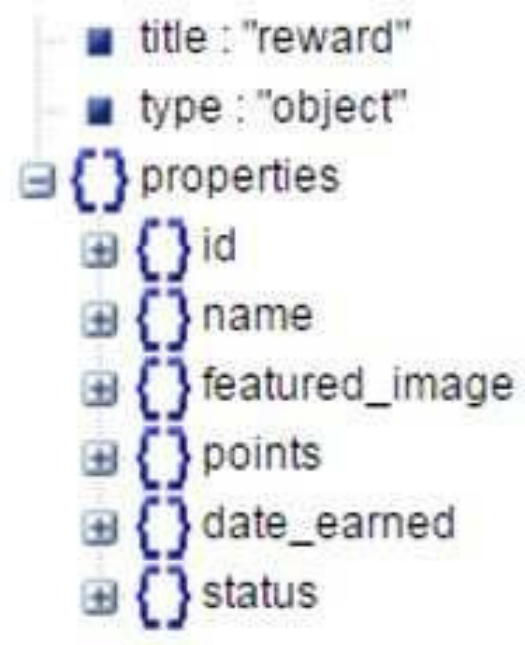

Fig. 12. Reward object, the full schema definition can be found at http //watersocial.org/extensions-json/rest/api/rewards/schema

to specifically target the game tasks. In the platform, the following task actions APIs are developed to support gamified social networking tasks and water use tasks. The use of these APIs can follow the pattern add_action(ACTION_NAME, CUSTOMISED_FUNCTION) in a WordPress plugin.

TABLE VI

GAME TASK ACTIONS APIS

\begin{tabular}{|l|l|} 
Action Name & Description \\
\hline publish_wateruse & $\begin{array}{l}\text { It can be used if a user uploads a } \\
\text { water use diary } \\
\text { It can be used if a user posts a } \\
\text { new question in Q\&A feature. } \\
\text { It can be used if a user posts an } \\
\text { answer in Q\&A feature. }\end{array}$ \\
publish_answer & $\begin{array}{l}\text { It can be used if a user } \\
\text { commented in social activity } \\
\text { stream. }\end{array}$ \\
posted & $\begin{array}{l}\text { It can be used if a user unlike or } \\
\text { like a topic. } \\
\text { It can be used if a user vote for an } \\
\text { answer/question in Q\&A feature. }\end{array}$ \\
ap_vote_casted & $\begin{array}{l}\text { It can be used if a user posts } \\
\text { some information on the map, e.g. } \\
\text { a photo or a tip. }\end{array}$ \\
publish_bgmp & $\begin{array}{l}\text { It can be used if a user replies a } \\
\text { topic. } \\
\text { It can be used if a user sends } \\
\text { invitation of join water social on } \\
\text { other social networks. }\end{array}$ \\
send_friend_invitation
\end{tabular}

\section{Inter-component Interactions: Evaluation}

Evaluation allows managers and researchers to continuously monitor and get the statistics of users, social network activities and rewards information. There are two components designed to handle these tasks, namely:
- Evaluation support (ES) is the component serves dashboard, it collects data from RS and IDS so that it can produces summative results of rewarding and all other social network activities occurred. ES performs different statistical features to produce the meaningful results.

- ISNP Dashboard (ID) This is a Web based application that presents the results generated from ES based upon a user's privilege.

The detailed description of the evaluation is beyond of this paper.

\section{DisSEMINATION OF WATERSOCIAL.ORG}

A number of dissemination activities were carried out between 1st January 2016 and 30th December 2016. To disseminate the WaterSocial.org the following types of activities were undertaken: 1 . Online activities: a) Social media: the use of social media platforms to share water saving messages. b)Publications: newsletters and blogs that detailed the WaterSocial platform. 2. Offline activities: a) Competitions: to enhance the gamification layer. b) School visits: pupil engagement that showcased the WaterSocial platform. These activities are related as they all publicised the WaterSocial platform by promoting water saving messages [4]. Their monitoring and analysis help in evaluating whether a measurable user uptake has been observed and the types of messages used and the degree of relevance to users. The results of the portal dissemination have been very satisfying, for example 102 new users were registered to WaterSocial.org, 127 friendships and 145 topics were created.

\section{ACKNOWLEDGMENT}

The research was undertaken as part of Integrated Support System for Efficient Water Usage and Resources Management (ISS-EWATUS) project, funded by European Union's Seventh Framework Programme for research, technological development and demonstration under grant agreement No. [619228].

\section{REFERENCES}

[1] http://issewatus.eu

[2] Magiera, E., Froelich, W.: Integrated support system for efficient water usage and resources management (iss-ewatus). Procedia Engineering 89, 1066/1072 (2014)

[3] Capiluppi a., Wang Z.: A Social-Centred Gamification Approach to Improve Household Water Use Efficiency, 7th International Conference on Games and Virtual Worlds for Serious Applications (VS-Games), DOI: 10.1109/VS-GAMES.2015.7295761, 2015

[4] Safa El-Jamal, A.C., Wang, Z.: A holistic dissemination strategy to deliver water conservation messages through gamication and social networks. In: Conference Water Efficency Network (WATEF). pp. 1/10 (2016)

[5] Binsted, A., Hutchins, R., Transport Research Laboratory (Great Britain). The role of social networking sites in changing travel behaviours. http://www.trl.co.uk/online_store/reports_publications/trl_ reports/cat_traffic_and_the_environment/report_the_role_of_social_ networking_sites_in_changing_travel_behaviours.htm, accessed 22/09/2014.

[6] Raacke, J., Bonds, J. MySpace and Facebook: Applying the uses and gratifications theory to exploring friend-networking sites. CyberPsychology \& Behavior, 11(2), pp. 169âĂŞ174, 2008.

[7] Jung, T., Youn, H., Mcclung, S. Motivations and self-presentation strategies on Korean-based âĂIJCyworldâĂ homepages. CyberPsychology \& Behavior, 10(1), pp. 24âĂŞ31, 2007. 
[8] Dunne, ÃĄ., Lawlor, M. -A., Rowley, J. Young people's use of online social networking sites âĂ $\mathrm{A}$ uses and gratifications perspective. Journal of Research in Interactive Marketing, 4(1), pp. 46âAS58, 2010

[9] Brandtzaeg P. and Heim J. Why People Use Social Networking Sites. In Proceedings of the $3 \mathrm{~d}$ International Conference on Online Communities and Social Computing: Held as Part of HCI International 2009 (OCSC '09), A. Ant Ozok and Panayiotis Zaphiris (Eds.). Springer-Verlag, Berlin, Heidelberg, pp. 143-152, 2009.

[10] Pattie, C., Seyd, P., Whiteley, P. Citizenship and civic engagement: Attitudes and behaviour in Britain. Political Studies, 51(3), pp. 443âĂŞ468, 2003.

[11] Fogg. BJ A behavior model for persuasive design. In Proceedings of the 4th International Conference on Persuasive Technology (Persuasive
'09). ACM, New York, NY, USA, Article 40, 7 pages, 2009.

[12] Barry W., Are personal communities local? A Dumptarian reconsideration, Social Networks, 18(4), pp. 347-354, 1996.

[13] McKenzie-Mohr, D. Fostering Sustainable Behavior: An Introduction to Community-Based Social Marketing. New York: New Society Publishers, 2011.

[14] Rolls, J. M. A review of Strategies Promoting Energy Related Behaviour Change. International Solar Energy Society Solar World Congress. Adelaide, South Australia 25th November-2nd December, 2001.

[15] Jackson, T. Motivating Sustainable Consumption: A review of evidence on consumer behaviour and behaviour change. Report to the Sustainable Development Research Network. Centre of Environmental Strategy, University of Surrey. Guilford, Surrey, 2005. 